\title{
Pre-donation BMI and preserved kidney volume can predict the cohort with unfavorable renal functional compensation at 1-year after kidney donation
}

Kazunobu Shinoda ${ }^{1,2^{*}}$ (D), Shinya Morita ${ }^{1}$, Hirotaka Akita ${ }^{3}$, Satoshi Tamaki ${ }^{1}$, Ryohei Takahashi ${ }^{1}$, Hidaka Kono ${ }^{4}$, Hiroshi Asanuma ${ }^{1}$, Eiji Kikuchi ${ }^{1}$, Masahiro Jinzaki ${ }^{3}$, Ken Nakagawa ${ }^{4}$ and Mototsugu Oya ${ }^{1}$

\begin{abstract}
Background: The magnitude of renal function recovery after kidney donation differs in donors with a heterogeneous background. Preoperative assessment of candidates with potentially unfavorable renal functional compensation is critical when baseline kidney function is marginal. We explored the significance of preserved kidney volume (PKV) and known preoperative risk factors for the prediction of unfavorable renal function compensation.

Methods: We enrolled 101 living donors for whom a 1-mm sliced enhanced computed tomography scan was performed preoperatively and clinical data could be collected up to 1 year after donation. The donors whose estimated glomerular filtration rate (eGFR) at 1 year after donation was 70\% or higher of baseline eGFR were assigned to the "favorable renal compensation" group and the others to the "unfavorable renal compensation" group.

Results: Age, sex, and preoperative serum uric acid level were not significant predictors for "unfavorable renal compensation." Multivariable logistic regression analysis revealed that body mass index (BMI) and body surface area (BSA)-adjusted PKV were independent preoperative risk factors for "unfavorable renal compensation" (adjusted odds ratio, 1.342 and 0.929, respectively). Hypertension and preoperative eGFR were not independent predictors when adjusted with BMI and BSA-adjusted PKV. Receiver operative characteristic analysis revealed that the predictive equation with the two independent predictors yielded a good accuracy to detect donor candidates with unfavorable renal functional compensation (area under the curve $=0.803$ ), and the optimal cut-off values were identified as $23.4 \mathrm{~kg} / \mathrm{m}^{2}$ for BMI and $107.3 \mathrm{~cm}^{3} / \mathrm{m}^{2}$ for BSA-adjusted PKV.
\end{abstract}

Conclusions: BMI and BSA-adjusted PKV may be useful to select candidates with potentially unfavorable renal function compensation before kidney donation.

Keywords: Kidney transplant donor, Renal function compensation, CT volumetry, BMI, Preserved kidney volume

\footnotetext{
* Correspondence: kshino49@yahoo.co.jp

${ }^{1}$ Department of Urology, Keio University School of Medicine, Tokyo 160-8582,

Japan

${ }^{2}$ Department of Nephrology, Toho University Faculty of Medicine, 7-5-23

Omorinishi Ota-ku, Tokyo 143-0015, Japan

Full list of author information is available at the end of the article
}

(c) The Author(s). 2019 Open Access This article is distributed under the terms of the Creative Commons Attribution 4.0 International License (http://creativecommons.org/licenses/by/4.0/), which permits unrestricted use, distribution, and reproduction in any medium, provided you give appropriate credit to the original author(s) and the source, provide a link to the Creative Commons license, and indicate if changes were made. The Creative Commons Public Domain Dedication waiver (http://creativecommons.org/publicdomain/zero/1.0/) applies to the data made available in this article, unless otherwise stated. 


\section{Background}

The prognosis of donors for living-related kidney transplantation has been of great concern for physicians, because otherwise they would be potentially healthy individuals. This issue has been argued and conflicting conclusions exist [1-6]. In several years ago, the majority argument was that cardiovascular disease risk or overall mortality risk in kidney transplant donors were comparable to those in matched non-donor population [1-3]. However, a recent report using a Norwegian cohort, which clearly disclosed exclusion criteria (e.g., age, body mass index [BMI], blood pressure [BP], BP medication, diabetes, and cardiovascular disease) of the donor and control cohorts, demonstrated that the risk of all-cause and cardiovascular deaths in the kidney donors was relatively higher than that in the controls. Furthermore, it showed that the risk of end-stage renal disease (ESRD) was unexpectedly much higher than in the controls (hazard ratio, 11.38) [4]. In the population of mixed races, black men, especially young black men, have the highest risk of developing ESRD in the late phase after donation [5,6]. Attaining a healthy condition and not developing chronic kidney disease (CKD) stage in lifetime for kidney donors is mandatory for physicians who grant permission to become a kidney donor. When baseline kidney function of donor candidates is marginal, it is very important to assess which candidates have a potential of unfavorable renal function compensation before kidney donation.

Several reports have proposed predicting factors for post-donation kidney function in kidney donors [5-8]. Age, obesity, hypertension, albuminuria, or pre-

donation kidney function are known risk factors for unfavorable renal function after donation. Many reports set the primary endpoint as net estimated glomerular filtration rate (eGFR) at some points postoperatively [6-8] and one report discussed the associated factors with the recovery of renal function after kidney donation [9]. Few reports have investigated preoperative factors that possibly affect the magnitude of renal function recovery after kidney donation. In the present study, we aimed to investigate the significant preoperative factors that could predict the candidates with a potential of unfavorable renal function compensation; the investigated outcome is not kidney function but the magnitude of renal function recovery after the donation. We used a new preoperative factor, calculated kidney volume of 3-dimensional (3-D) reconstruction by thin-sliced computed tomography (CT) scan, as a candidate of significant risk factor instead of split renal function by scintigraphy because it was recently reported that $\mathrm{CT}$ volumetry is superior to renal scintigraphy for prediction of preserved kidney function [10].

\section{Methods}

\section{Ethics statement}

This study was conducted in compliance with the ethical standards of the Declaration of Helsinki and was approved by the research ethics committee of Keio University School of Medicine (authorization number, 2018-0130). The research ethics committee approved waiving informed consent from participants because this was a retrospective and noninvasive study.

\section{Patient selection}

Between April 2000 and September 2014, we performed 144 donor nephrectomies for living-related kidney transplantation. Among them, we retrospectively enrolled 101 patients for whom 1-mm thin-sliced enhanced CT was performed before kidney donation. All patients were Japanese. Clinical data were collected periodically at least up to a year postoperatively. All surgeries were performed via a laparoscopic procedure at our institute. We excluded patients with diabetes or glucose intolerance, those with urinary albumin excretion was $\geq 30 \mathrm{mg} / \mathrm{gCreatinine}(\mathrm{Cr})$, and those with preceding coronary or other heart diseases.

\section{CT volumetry}

Preoperative dynamic CT was performed using 16- or 64-multidetector CT scanners (LightSpeed Pro16, LightSpeed VCT, BrightSpeed, and Discovery CT750 HD; GE Healthcare, Waukesha, WI, USA) with a bolus-tracking technique. Iodinated contrast media (iohexol, Omnipaque 300; Daiichi Sankyo, Tokyo, Japan) at a dose of 2 $\mathrm{mL} / \mathrm{kg}$ was injected for $30 \mathrm{~s}$ using a power injector following unenhanced CT scan. The region-of-interest cursor for bolus tracking was placed in the aorta at the celiac axis level. Acquisition of the corticomedullary phase started $12 \mathrm{~s}$ after reaching the threshold of 150 Hounsfield units. The nephrographic phase (Fig. 1a) was acquired at $55 \mathrm{~s}$ after acquisition of the corticomedullary phase. The excretory phase started $8 \mathrm{~min}$ after contrast injection. The nephrographic phase images were transferred and analyzed on a dedicated workstation (AW server 2.0-12.0; GE Healthcare). The kidney contour was semiautomatically drawn after a mouse click on the renal parenchyma with pixels of the same CT values being united on an axial plane (Fig. 1b). The software semiautomatically reconstructed a 3-D image of the kidney by accumulating 1-mm sliced axial images and calculated the kidney volume. Structures other than renal parenchyma (e.g., renal cyst, renal vessels, or collecting system) were eliminated from the reconstructed kidney (Fig. 1c). We measured total kidney volume $\left(\mathrm{cm}^{3}\right)$ and preserved kidney volume (PKV). We also calculated body surface area (BSA)-adjusted PKV (BSA-adjusted PKV): BSA-adjusted PKV $=$ PKV/BSA $\left(\mathrm{cm}^{3} / \mathrm{m}^{2}\right)$. 


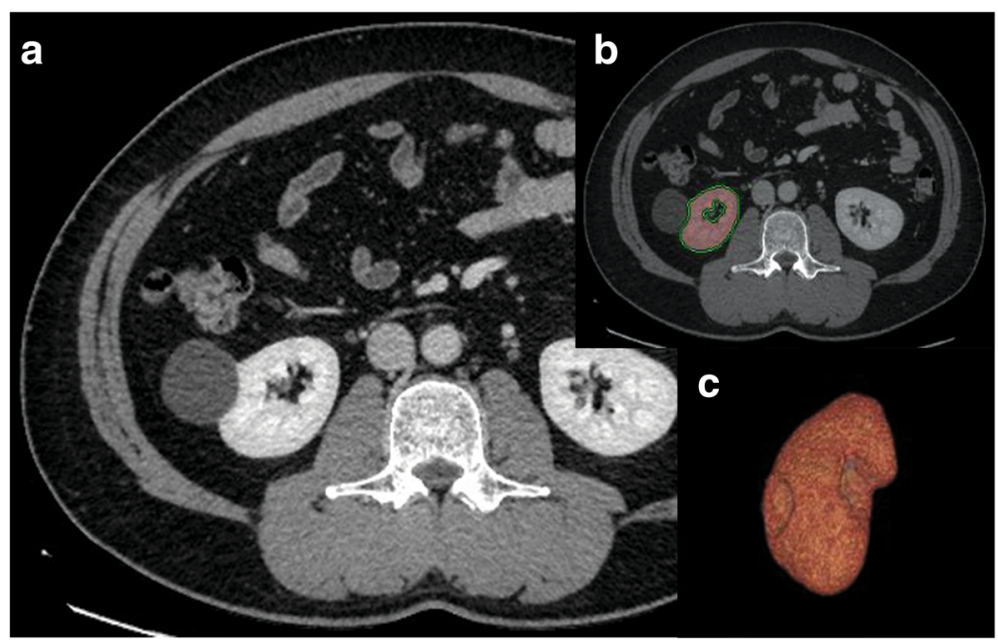

Fig. 1 Representative semiautomatic calculation of kidney volume using 3-D reconstruction methods. a An axial plane of the nephrographic phase in a representative patient. $\mathbf{b}$ The kidney contour was semiautomatically drawn with pixels of the same CT values being united on an axial plane. c 3-D reconstructed image was created automatically and the volumetry was performed

\section{Renal function assessment and study design}

Preoperative renal function was assessed by 24-h creatinine clearance $(\mathrm{CCr})$ evaluation and eGFR calculation. $\mathrm{CCr}$ was calculated by the following equation: $\mathrm{CCr}(\mathrm{mL} /$ $\left.\mathrm{min} / 1.73 \mathrm{~m}^{2}\right)=($ urine $\mathrm{Cr}[\mathrm{mg} / \mathrm{dL}] \times 24-\mathrm{h}$ urine volume $[\mathrm{mL}]) / 24 / 60 /$ serum $\mathrm{Cr}(\mathrm{mg} / \mathrm{dL}) \times 1.73 / \mathrm{BSA} . \quad \mathrm{BSA}$ $=(\text { weight })^{0.425} \times(\text { height })^{0.725} \times 0.0007184$ [11]. Postoperative renal function was assessed by eGFR calculation. We used two different equations for eGFR calculation. The first one was the Modification of Diet in Renal Disease (MDRD) equation modified for Japanese patients [12]: eGFR $=194 \times$ serum $\mathrm{Cr}^{-1.094} \times \mathrm{Age}^{-0.287} \times 0.739$ (if female). The second one was the equation of CKD-EPI formula for white or other [13]: eGFR $=141 \times(\text { serum } \mathrm{Cr} / 0.9)^{-}$ $0.411 \times(0.993)^{\text {Age }}$ (if male \& $\left.\mathrm{Cr} \leq 0.9 \mathrm{mg} / \mathrm{dL}\right)$; eGFR $=$ $141 \times(\text { serum } \mathrm{Cr} / 0.9)^{-1.209} \times(0.993)^{\text {Age }}$ (if male \& $\mathrm{Cr}>0.9$ $\mathrm{mg} / \mathrm{dL}) ; \quad$ eGFR $=144 \times(\text { serum } \mathrm{Cr} / 0.7)^{-0.329} \times(0.993)^{\text {Age }} \quad$ (if female \& $\mathrm{Cr} \leq 0.7 \mathrm{mg} / \mathrm{dL}) ;$ eGFR $=144 \times(\text { serum } \mathrm{Cr} / 0.7)^{-}$ $1.209 \times(0.993)^{\text {Age }}$ (if female \& $\mathrm{Cr}>0.7 \mathrm{mg} / \mathrm{dL}$ ). We compared preoperative $\mathrm{CCr}$ with two different eGFR formulas in order to decide the optimal eGFR equation for this study.

We categorized the kidney donors into two groups. Patients whose eGFR at 1 year after donation was $\geq 70 \%$ of their pre-donation eGFR were assigned to the "favorable renal compensation" group, and those whose eGFR at 1 year after donation was $<70 \%$ of their pre-donation eGFR were assigned to the "unfavorable renal compensation" group. Delanaye P et al. conducted a literature review about post-donation renal function and mentioned that many studies reported post-donation renal function as $65-70 \%$ of the base line [14]. Therefore, we determined the threshold between the "unfavorable renal compensation" and "favorable renal compensation" groups as $70 \%$ eGFR of the base line. The investigated variables included age (years), sex (female), height (m), weight $(\mathrm{kg})$, BMI $\left(\mathrm{kg} / \mathrm{m}^{2}\right)$, hypertension (defined as the use of antihypertensive drugs), total kidney volume $\left(\mathrm{cm}^{3}\right)$, PKV, BSA-adjusted PKV, PKV ratio (\%), preoperative serum uric acid $(\mathrm{mg} / \mathrm{dL})$, preoperative serum $\mathrm{Cr}$ $(\mathrm{mg} / \mathrm{dL})$, preoperative $\mathrm{CCr}\left(\mathrm{mL} / \mathrm{min} / 1.73 \mathrm{~m}^{2}\right)$, preoperative eGFR $\left(\mathrm{mL} / \mathrm{min} / 1.73 \mathrm{~m}^{2}\right)$, eGFR at 1-year after kidney donation $\left(\mathrm{mL} / \mathrm{min} / 1.73 \mathrm{~m}^{2}\right)$, and percent change of 1 -year eGFR. BMI was calculated by the following equation: BMI $\left(\mathrm{kg} / \mathrm{m}^{2}\right)=$ weight $(\mathrm{kg}) /(\text { height }[\mathrm{m}])^{2}$.

\section{Statistical analyses}

Results are presented as median and range of distribution for continuous variables and number and percentage for categorical variables (Table 1). Differences between the "favorable" and "unfavorable" renal compensation groups were compared using $X^{2}$ statistics for categorical variables and the Wilcoxon rank sum test for non-normally distributed data or a $t$-test for normally distributed data. To predict the probability of the outcome, that is " $\%$ change of 1 -year eGFR" being $\geq 70 \%$ of pre-donation eGFR, we conducted multivariable logistic regression analysis. Coefficients, crude odds ratio (OR), adjusted OR, and Wald $\chi^{2}$ for each covariate are shown in Tables 2 and 3. Probability $(p)$ values of $<0.05$ were considered statistically significant. In addition, we drew receiver operating characteristic (ROC) curve of the predictive equation and the area under the curve (AUC) was calculated. Statistical analysis was performed using $\mathrm{JMP}^{\circ}$ Pro v 13.2.0 (SAS Institute, Inc., Cary, NC, USA) and statistical figures were drawn using GraphPad Prism v 5.0 (GraphPad Software, San Diego, CA, USA). 
Table 1 Demographic and clinical characteristics of the unfavorable and favorable renal compensation cohorts

\begin{tabular}{|c|c|c|c|}
\hline Variables & $\begin{array}{l}\text { Unfavorable renal compensation } \\
\text { (\%change of } 1 \text {-year eGFR }<70 \%) \\
(n=61)\end{array}$ & $\begin{array}{l}\text { Favorable renal compensation } \\
(\% \text { change of } 1 \text {-year eGFR } \geq 70 \%) \\
(n=40)\end{array}$ & $p$ value \\
\hline Age (years) & $59(33-79)$ & $56(31-71)$ & 0.6644 \\
\hline Sex (female) & $31(51 \%)$ & $25(63 \%)$ & 0.3075 \\
\hline Height (m) & $1.62(1.47-1.78)$ & $1.60(1.50-1.81)$ & 0.5389 \\
\hline Weight (kg) & $60.2(41.9-93.5)$ & $55.0(39-76.1)$ & 0.0026 \\
\hline $\mathrm{BMI}\left(\mathrm{kg} / \mathrm{m}^{2}\right)$ & $24.0(15.7-31.8)$ & $21.7(16.9-26.6)$ & 0.0009 \\
\hline Hypertension & $15(25 \%)$ & $3(8 \%)$ & 0.0341 \\
\hline Total kidney volume $\left(\mathrm{cm}^{3}\right)$ & $343.7(215.1-494.4)$ & $348.2(250.9-499.8)$ & 0.4061 \\
\hline Preserved kidney volume $\left(\mathrm{cm}^{3}\right)$ & $161.5(103.6-226.8)$ & $169.4(124.0-235.9)$ & 0.3667 \\
\hline Body surface area-adjusted preserved kidney volume $\left(\mathrm{cm}^{3} / \mathrm{m}^{2}\right)$ & $98.8(76.2-119.8)$ & $107.5(85.3-138.8)$ & 0.0009 \\
\hline Preserved kidney volume ratio (\%) & $49.2(44.3-53.4)$ & $49.5(43.5-59.1)$ & 0.3983 \\
\hline Preoperative serum uric acid (mg/dL) & $5.4(3.7-7.8)$ & $5.5(0.7-8.6)$ & 0.5203 \\
\hline Preoperative serum creatinine (mg/dL) & $0.79(0.50-1.10)$ & $0.67(0.41-1.02)$ & 0.0021 \\
\hline Preoperative creatinine clearance $\left(\mathrm{mL} / \mathrm{min} / 1.73 \mathrm{~m}^{2}\right)$ & $112.5(78.8-168.1)$ & $124.9(76.1-175.4)$ & 0.0287 \\
\hline Preoperative eGFR (mL/min/1.73 m²) & $93.2(65.5-118.9)$ & $97.8(81.8-129.6)$ & 0.0014 \\
\hline eGFR at 1-year after kidney donation $\left(\mathrm{mL} / \mathrm{min} / 1.73 \mathrm{~m}^{2}\right)$ & $57.9(37.6-81.3)$ & $75.6(59.5-121.6)$ & $<.0001$ \\
\hline \%change of 1-year eGFR & $62.9(49.3-69.4)$ & $75.4(70.5-93.8)$ & $<.0001$ \\
\hline
\end{tabular}

Data are $\mathrm{n}(\%)$ or median (range)

\section{Results}

\section{Comparison of preoperative eGFR and CCr}

We first assessed the correlation between preoperative eGFR of two different equations (modified MDRD equation for Japanese and CKD-EPI equation) and $\mathrm{CCr}$ by using Bland-Altman plot analysis. The mean difference between $\mathrm{CCr}$ and modified MDRD eGFR was $-40.4 \mathrm{~mL} / \mathrm{min} / 1.73 \mathrm{~m}^{2}$ (95\% confidence interval [CI]: -44.0 to $-36.9 \mathrm{~mL} / \mathrm{min} / 1.73 \mathrm{~m}^{2}$ ) (Fig. 2a). The correlation coefficient of this analysis was 0.658. Meanwhile, the mean difference between $\mathrm{CCr}$ and CKD-EPI eGFR was $-19.4 \mathrm{~mL} / \mathrm{min} / 1.73 \mathrm{~m}^{2}$ (95\% CI: -22.8 to $-16.0 \mathrm{~mL} / \mathrm{min} / 1.73 \mathrm{~m}^{2}$ ) (Fig. $2 \mathrm{~b}$ ). The correlation coefficient of this analysis was 0.725 . These results demonstrated that modified MDRD eGFR more underestimated $\mathrm{CCr}$ in each individual. Therefore, we decided to use the CKD-EPI equation for eGFR calculation in our cohort.

\section{Univariate analysis of each variable between the "favorable" and "unfavorable" renal compensation groups}

Table 1 demonstrates the characteristics of 101 patients who were assigned in the "unfavorable renal compensation" or "favorable renal compensation" groups by using modified MDRD equation of eGFR for the Japanese population (40 and 61 in the "favorable" and "unfavorable" renal compensation groups, respectively). Median weight and BMI were significantly higher in the "unfavorable" than in the "favorable" renal compensation groups $(60.2$ vs. $55.0 \mathrm{~kg}, p=0.0026$ and 24.0 vs. 21.7 $\mathrm{kg} / \mathrm{m}^{2}, p=0.0009$, respectively). The ratio of donors with hypertension was significantly higher in the "unfavorable" than in the "favorable" renal compensation groups (25 vs. $8 \%, p=0.0341$, respectively). Preoperative characteristics, including age, sex, height, PKV ratio, and serum uric acid levels, were not significantly

Table 2 Multivariable logistic regression analysis to determine independent predictors for unfavorable renal compensation at 1-year post kidney donation

\begin{tabular}{llllll}
\hline & $\beta(\mathrm{S} . \mathrm{E})$. & Wald Chisquare & Crude OR (95\% Cl) & Adjusted OR (95\% Cl) & $p$ value \\
\hline Hypertension & $-0.597(0.476)$ & 1.574 & $4.022(1.082-14.950)$ & $3.300(0.511-21.230)$ & 0.2096 \\
Preoperative eGFR $\left(\mathrm{mL} / \mathrm{min} / 1.73 \mathrm{~m}^{2}\right)$ & $-0.056(0.032)$ & 3.105 & $0.933(0.893-0.975)$ & $0.946(0.889-1.006)$ & 0.0780 \\
BMI $\left(\mathrm{kg} / \mathrm{m}^{2}\right)$ & $0.294(0.109)$ & 7.228 & $1.285(1.097-1.506)$ & $1.342(1.083-1.663)$ & 0.0026 \\
Body surface area-adjusted preserved kidney volume $\left(\mathrm{cm}^{3} / \mathrm{m}^{2}\right)$ & $-0.074(0.025)$ & 9.109 & $0.923(0.891-0.970)$ & $0.929(0.885-0.974)$ & 0.0009 \\
\hline
\end{tabular}


Table 3 Multivariable logistic regression analysis by using the independent covariates in Table 2

\begin{tabular}{llllll}
\hline & $\beta($ S.E. $)$ & Wald Chisquare & Crude OR (95\% Cl) & Adjusted OR (95\% Cl) & $p$ value \\
\hline BMI $\left(\mathrm{kg} / \mathrm{m}^{2}\right)$ & $0.309(0.100)$ & 9.455 & $1.285(1.097-1.506)$ & $1.361(1.137-1.692)$ & 0.0004 \\
Body surface area-adjusted preserved kidney volume $\left(\mathrm{cm}^{3} / \mathrm{m}^{2}\right)$ & $-0.088(0.024)$ & 13.070 & $0.923(0.891-0.970)$ & $0.916(0.869-0.957)$ & $<.0001$ \\
\hline
\end{tabular}

different between the two groups by univariate statistical analyses.

Although total kidney volume and PKV were not statistically different between the groups, BSA-adjusted PKV was significantly higher in the "favorable" renal compensation group than in the "unfavorable" one (107.5 vs. $98.8 \mathrm{~cm}^{3}, p=0.0009$ ).

Median preoperative $\mathrm{Cr}$ was significantly higher in the "unfavorable" renal compensation group than in the "favorable" one ( 0.79 vs. $0.67 \mathrm{mg} / \mathrm{dL}, p=0.0021$, respectively). Median preoperative $\mathrm{CCr}$ and eGFR were significantly lower in the "unfavorable" renal compensation group than in the "favorable" one $(112.5$ vs. $124.9 \mathrm{~mL} / \mathrm{min} /$ $1.73 \mathrm{~m}^{2}, p=0.0287$ and 93.2 vs. $97.8 \mathrm{~mL} / \mathrm{min} / 1.73 \mathrm{~m}^{2}$, $p=0.0014$, respectively).

Median eGFR at 1 year after kidney donation and median percent change of 1-year eGFR were significantly higher in the "favorable" renal compensation group than in the "unfavorable" one $\left(75.6\right.$ vs. $57.9 \mathrm{~mL} / \mathrm{min} / 1.73 \mathrm{~m}^{2}$, $p<.0001$ and $75.4 \%$ vs. $62.9 \%, p<.0001$, respectively).

\section{Independent predictors for unfavorable renal} compensation at 1 year after kidney donation

We subsequently performed multivariable logistic regression analysis using significant covariates that were obtained in the univariate analysis (hypertension, preoperative eGFR, BMI, and BSA-adjusted PKV) to determine the independent predictors for unfavorable renal compensation at 1 year after kidney donation. We did not include weight, $\mathrm{Cr}$, and $\mathrm{CCr}$ because these covariates potentially interact with BMI or preoperative eGFR.

When hypertension, preoperative eGFR, BMI, and BSA-adjusted PKV were adjusted together, it became evident that BMI (adjusted OR, 1.342; 95\% CI, 1.0831.663; $p=0.0026$ ), and BSA-adjusted PKV (adjusted OR, $0.929 ; 95 \% \mathrm{CI}, 0.885-0.974 ; p=0.0009)$ were independent predictors for eGFR decline $>30 \%$ at 1 year after kidney donation (Tables 2). This result indicated that hypertension and preoperative eGFR were not independent predictors for unfavorable renal compensation. Tests by entering interaction terms for each covariate into the logistic regression analysis revealed no interaction among hypertension, preoperative eGFR, BMI, and BSA-adjusted PKV (data not shown). When BMI and BSA-adjusted PKV were adjusted together, each coefficient was 0.309 and -0.088 , respectively (Table 3 ). Therefore, the logit probability for the outcome of unfavorable renal function compensation was as follows: logit $(p)=(0.309 \times \mathrm{BMI})+(-0.088 \times \mathrm{BSA}$-adjusted PKV) +2.443 .

A whole model test (comparing the model in Table 3 to the model including intercept only) denoted that the model in Table 3 was significant $\left(x^{2}, 26.838, p<.0001\right)$. A lack of fit test indicated that the model contained sufficient numbers of covariates and the linear model appropriately fit the data $\left(\chi^{2}, 92.231, p=0.2775\right)$.
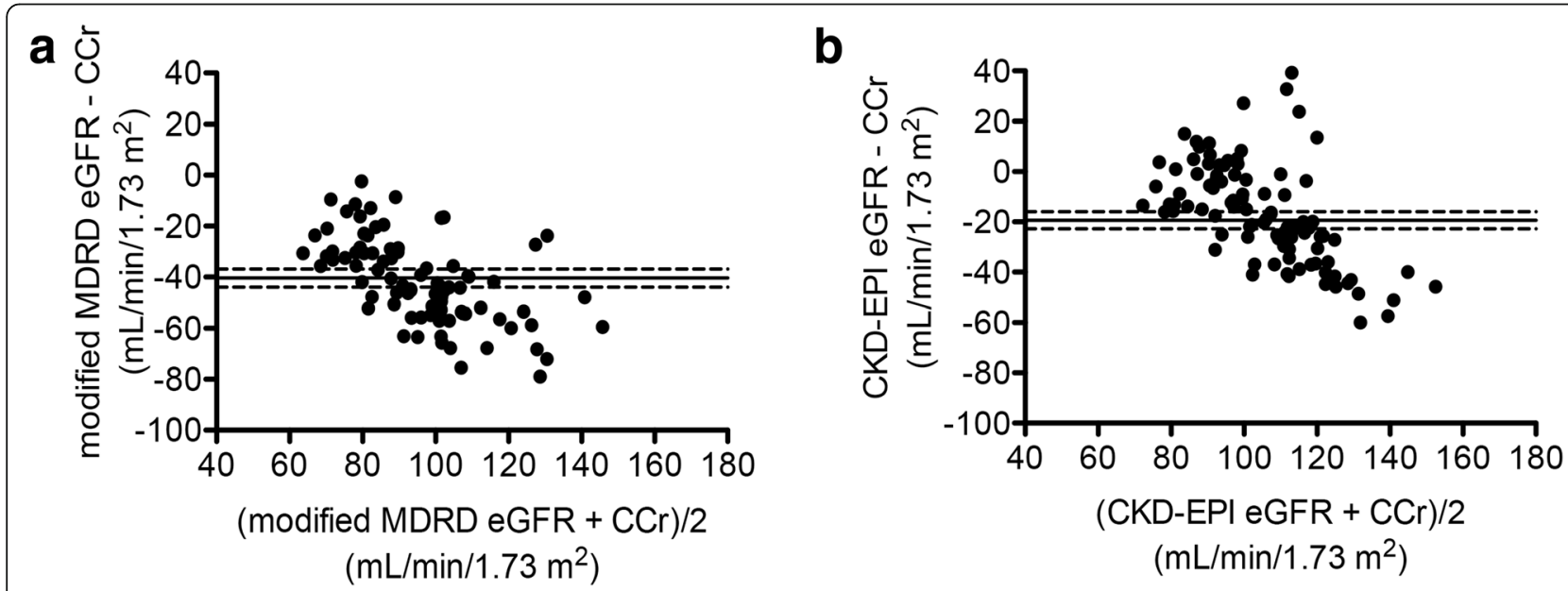

Fig. 2 Bland-Altman plots for the comparison between preoperative CCr and two different eGFR equations. a Comparison between preoperative CCr and modified MDRD eGFR for Japanese. b Comparison between preoperative CCr and CKD-EPI eGFR. The X-axis represents the mean of each eGFR and CCr. The Y-axis represents the difference between CCr and each eGFR. Dots represent data of each donor. The horizontal continuous lines represent the average of the difference between CCr and eGFR, and dashed lines represent $95 \% \mathrm{Cl}$ 
Diagnostic accuracy evaluation of the predictive model and cut-off values of BMI and BSA-adjusted PKV

The ROC analysis showed a strong diagnostic accuracy of the predictive equation using independent predictors, BMI and BSA-adjusted PKV to predict the donors with unfavorable renal functional compensation (AUC, 0.803; 95\% CI, 0.712-0.895; Fig. 3). The ROC curve also identified the optimal cut-off values of $23.4 \mathrm{~kg} / \mathrm{m}^{2}$ for BMI and $107.3 \mathrm{~cm}^{3} / \mathrm{m}^{2}$ for BSA-adjusted PKV.

\section{Discussion}

Our findings demonstrated that BMI, and BSA-adjusted PKV calculated by the 3-D reconstructed image using a thin-sliced CT scan were significant preoperative predictors for patients who lose $>30 \%$ of eGFR at 1 year after kidney donation. Moreover, multivariable logistic regression analysis revealed that pre-donation eGFR (CKD-EPI) was not an independent predictor for the magnitude of renal function compensation after kidney donation. PKV may surpass the baseline eGFR in the point to give information for predicting the magnitude of renal function compensation after kidney donation.

The significance of preserved kidney volumetry by CT scan in kidney transplant donors has been argued mostly in terms of a potential substitute for nuclear renography [10, 15-18], a predictor for CKD stage 3 after donation [19], or a predictor for post-donation eGFR [20, 21]. This study differs from the previous studies because we investigated whether BSA-adjusted PKV is useful in the prediction of unfavorable renal functional compensation, in other words unfavorable adaptive hyperfiltration, not post-donation renal function. Studies about the usefulness of CT volumetry as a predictor for the magnitude of adaptive hyperfiltration after kidney donation are very rare. Jeon et al. [22] reported that lower preoperative volume of the remaining kidney was an independent predictor of delayed renal function recovery after kidney

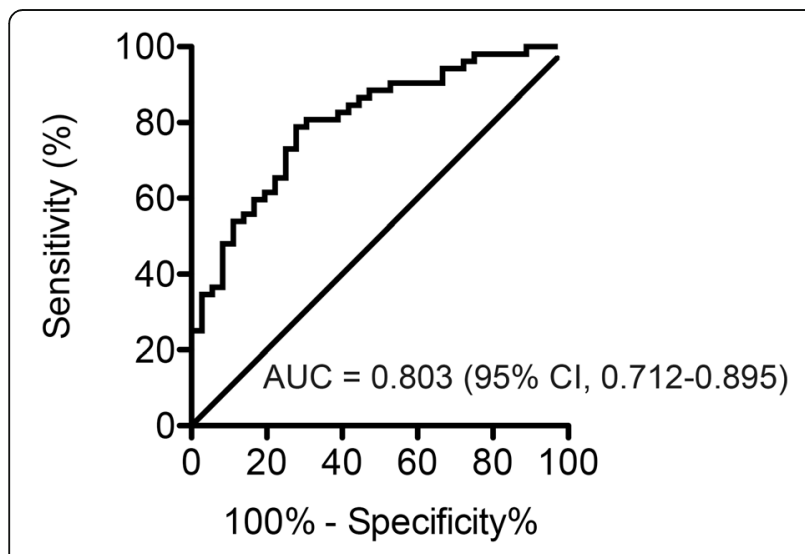

Fig. 3 The diagnostic accuracy evaluation for the predictive equation using BMI and BSA-adjusted PKV by ROC curve. AUC and its $95 \% \mathrm{Cl}$ are also shown donation. However, they defined the cohort of delayed renal function recovery as that having eGFR $<60 \mathrm{~mL} / \mathrm{min} / 1.73$ $\mathrm{m}^{2}$ without comparison with preoperative renal function, which may lack the accuracy in estimating compensatory hypertrophy. Lenihan et al. [23] reported the very interesting study about the mechanism of adaptive hyperfiltration after kidney donation in terms of glomerular dynamics. Their model explains the glomerular filtration by introducing four determinants, which are renal plasma flow (RPF), glomerular transcapillary hydraulic pressure, plasma oncotic pressure, and glomerular-filtering surface area. They showed that adaptive hyperfiltration was maintained at a constant level for many years after kidney donation, which, in other words, is benign hyperfiltration after living kidney donation [24]. They found that the increase in RPF and glomerular-filtering surface area, in other words glomerular hypertrophy or glomerular volume increase, was constantly observed in parallel for 6-8 years after kidney donation. Their findings well explained how post-donation hyperfiltration is maintained without the relation to the excessive increase in glomerular hydraulic pressure. Moreover, they demonstrated that glomerular-filtering surface area is significantly correlated with renocortical volume. Inferring the evidence above, the higher kidney volume is related to higher glomerular-filtering surface area, which in turn may lead to higher magnitude of adaptive hyperfiltration after kidney donation.

Obesity has been suggested as a risk factor for kidney function insufficiency after donor nephrectomy $[7,25,26]$ or unilateral nephrectomy in non-donor patients $[27,28]$. However, the underlying mechanisms of kidney function insufficiency caused by obesity in patients undergoing nephrectomy have not been clearly explained. Weisinger et al. [29] first suggested obesity-related glomerulopathy by detecting focal segmental glomerulosclerosis and reversible nephrotic range proteinuria in extremely obese patients. Whether the kidneys from obese donors, who, other than having obesity, are relatively closer to the healthy cohort than the cohort with obesity-related glomerulopathy, have some histologic damage is of great concern. Rea et al. [30] compared implant biopsy specimens from obese and nonobese donors and did not identify any difference in chronic histologic damage between these two groups. On the other hand, Ohashi et al. [26] reported more prominent chronic histologic changes in implant biopsy specimens from donors with metabolic syndrome. Interestingly, Rea et al. [30] noted that the biopsy specimens from obese donors contained larger glomerular planar surface area compared to those from the non-obese cohort and they also detected dilated tubules in obese donors. Another report also showed that BMI is correlated positively with glomerular cross-sectional area [31]. These findings may reflect the phenomenon that the kidneys in obese donors are 
relatively shifted to the hyperfiltration state. This may explain why adaptive hyperfiltration after kidney donation in obese donors is less satisfactory than that in non-obese donors. In fact, Choi et al. [28] demonstrated that the magnitude of adaptive hyperfiltration was lower in extremely obese non-donor patients who underwent nephrectomy.

The reason why known predictive factors, such as age or hypertension were not significant covariates in the multivariable logistic regression analysis is another concern. Several studies suggested that age and pre-donation hypertension were negatively correlated with post-donation renal function [6-8]. On the other hand, some reports suggested that relatively high-risk donors, including those with older age or preexisting hypertension, exert similar post-donation renal function or compensatory hypertrophy compared to low-risk donors [32, 33]. One speculation is that follow-up of up to 5 years after kidney donation may be relatively short when evaluating the effect of these risk factors on post-donation renal compensation in the cohort of strictly-selected living kidney donors [32, 33]. They are relatively younger and less hypertensive compared to patients undergoing nephrectomy for cancers or reasons other than kidney donation. Although preserved kidneys in such high-risk donors exert favorable compensatory hypertrophy or adaptive hyperfiltration capacity after kidney donation, the more prominent glomerulopenia was actually observed [34, 35]. The investigators considered that such high-risk donors need careful long-term follow-up. Fesler et al. [36] argued from a different viewpoint. They noted that increased arterial stiffness measured by carotid-to-femoral pulse wave velocity is an independent risk factor for decreased post-donation compensatory hyperfiltration, although baseline BP was not correlated with adaptive glomerular hyperfiltration. Further validation studies are required to evaluate if arterial stiffness reflects a decreased capacity in baseline renal hemodynamics.

We must acknowledge some limitations of our study. Our study had a single-institution retrospective design and sample size was relatively small. The 1-year follow-up was relatively short. However, the aim of this study is to select eligible candidates among marginal living donors by evaluating a potential of renal function compensation in a short term after the operation. Living kidney donation from donor candidates with marginal renal function and unfavorable compensation in a short term after kidney donation should be prohibited. In our study, donors with hypertension were defined as those taking antihypertensive medication and their BP was already corrected in the normal range. This might weaken the power of hypertension as a covariate in our study. However, it should be considered that the studies using kidney transplant donors tend not to include untreated or drug-resistant hypertensive patients. In addition, evaluation of renal function should be done basically by using measured GFR, although we had to use eGFR for assessment of renal function.

\section{Conclusions}

Before kidney donation, we can predict which candidates have a potential of unfavorable renal function compensation using preoperative BMI and calculation of PKV. Predicting the magnitude of renal function compensation before operation may be helpful to assess the eligibility of kidney donor candidates when their baseline kidney function is marginal.

\section{Abbreviations \\ 3-D: 3-dimensional; AUC: Area under the curve; BMI: Body mass index; BP: Blood pressure; BSA: Body surface area; CCr: Creatinine clearance; $\mathrm{Cl}$ : Confidence interval; CKD: Chronic kidney disease; Cr: Creatinine; $C T$ : Computed tomography; eGFR: Estimated glomerular filtration rate; ESRD: End-stage renal disease; MDRD: Modification of Diet in Renal Disease OR: Odds ratio; PKV: Preserved kidney volume; ROC: Receiver operating characteristic; RPF: Renal plasma flow}

\section{Acknowledgements}

The authors thank the living donor and recipient coordinators Yuka Izawa, Chie Takaoka, and Etsuko Soeda.

\section{Ethical approval and consent to participate}

This study was conducted in compliance with the ethical standards of the Declaration of Helsinki and was approved by the research ethics committee of Keio University School of Medicine (authorization number, 2018-0130). The research ethics committee approved waiving informed consent from participants because this was a retrospective and noninvasive study.

Funding

The authors did not receive any funding for this work.

Availability of data and materials

The datasets analyzed during the current study are available from the corresponding author on reasonable request.

\section{Authors' contributions}

K.S. participated in research design, writing of the paper, performance of the research, collecting the data, and analyzing data. S. M. participated in research design and collecting the data. H.A. 1 participated in research design, writing of the paper, and analyzing data. S.T. participated in research design and collecting the data. R.T. participated in research design and collecting the data. H.K. participated in research design and collecting the data. H.A. 2 participated in research design and analyzing data. E.K. participated in research design and analyzing data. K.N. participated in research design and analyzing data. M.J. participated in research design, writing of the paper, and analyzing data. M.O. participated in research design, writing of the paper, and analyzing data. All authors have read and approved of the final version of the manuscript.

Consent for publication

Not applicable.

Competing interests

The authors declare that they have no competing interests.

\section{Publisher's Note}

Springer Nature remains neutral with regard to jurisdictional claims in published maps and institutional affiliations. 


\section{Author details}

'Department of Urology, Keio University School of Medicine, Tokyo 160-8582, Japan. ${ }^{2}$ Department of Nephrology, Toho University Faculty of Medicine, 7-5-23 Omorinishi Ota-ku, Tokyo 143-0015, Japan. ${ }^{3}$ Department of Diagnostic Radiology, Keio University School of Medicine, Tokyo 160-8582, Japan. ${ }^{4}$ Department of Urology, Tokyo Dental College Ichikawa General Hospital, Chiba 272-8513, Japan

Received: 20 November 2018 Accepted: 30 January 2019 Published online: 08 February 2019

\section{References}

1. Ibrahim HN, Foley R, Tan L, Rogers T, Bailey RF, Guo H, et al. Long-term consequences of kidney donation. N Engl J Med. 2009;360:459-69.

2. Mjoen G, Reisaeter A, Hallan S, Line PD, Hartmann A, Midtvedt K, et al. Overall and cardiovascular mortality in Norwegian kidney donors compared to the background population. Nephrol Dial Transplant. 2012;27:443-7.

3. Garg AX, Meirambayeva A, Huang A, Kim J, Prasad GV, Knoll G, et al. Cardiovascular disease in kidney donors: matched cohort study. BMJ. 2012; 344:e1203

4. Mjoen G, Hallan S, Hartmann A, Foss A, Midtvedt K, Oyen O, et al. Longterm risks for kidney donors. Kidney Int. 2014;86:162-7.

5. Muzaale AD, Massie AB, Wang MC, Montgomery RA, McBride MA, Wainright $J L$, et al. Risk of end-stage renal disease following live kidney donation. JAMA. 2014;311:579-86.

6. Grams ME, Sang Y, Levey AS, Matsushita K, Ballew S, Chang AR, et al. Kidney-failure risk projection for the living kidney-donor candidate. N Engl J Med. 2016:374:411-21.

7. Rook M, Bosma RJ, van Son WJ, Hofker HS, van der Heide JJ, ter Wee PM, et al. Nephrectomy elicits impact of age and BMI on renal hemodynamics: lower postdonation reserve capacity in older or overweight kidney donors. Am J Transplant. 2008;8:2077-85.

8. Hosokawa Y, Tanaka N, Mibu H, Anai S, Torimoto K, Yoneda T, et al. Followup study of unilateral renal function after nephrectomy assessed by glomerular filtration rate per functional renal volume. World I Surg Oncol. 2014;12:59.

9. Na JC, Park JS, Yoon MG, Lee HH, Yoon YE, Huh KH, et al. Delayed recovery of renal function after donor nephrectomy. Transplant Proc. 2018;50:1022-4.

10. Barbas AS, Li Y, Zair M, Van JA, Famure O, Dib MJ, et al. CT volumetry is superior to nuclear renography for prediction of residual kidney function in living donors. Clin Transpl. 2016;30:1028-35.

11. Bois D, DBE D. A formula to estimate the approximate surface area if height and weight be known. Arch Intern Med. 1916;17:863-71.

12. Matsuo S, Imai E, Horio M, Yasuda Y, Tomita K, Nitta K, et al. Revised equations for estimated GFR from serum creatinine in Japan. Am J Kidney Dis. 2009;53:982-92.

13. Levey AS, Stevens LA, Schmid CH, Zhang YL, Castro AF 3rd, Feldman HI, et al. A new equation to estimate glomerular filtration rate. Ann Intern Med. 2009:150:604-12.

14. Delanaye P, Weekers L, Dubois BE, Cavalier E, Detry O, Squifflet JP, et al. Outcome of the living kidney donor. Nephrol Dial Transplant. 2012;27:41-50,

15. Lee HH, Han WK, Kang SK, Huh KH, Kim MS, Kim Sl, et al. Usefulness of multi-detector computed tomography scanning as a replacement for Diethylenetriamine Pentaacetic acid. Transplant Proc. 2017;49:1023-6.

16. Diez A, Powelson J, Sundaram CP, Taber TE, Mujtaba MA, Yaqub MS, et al. Correlation between CT-based measured renal volumes and nuclearrenography-based split renal function in living kidney donors. Clinical diagnostic utility and practice patterns. Clin Transpl. 2014;28:675-82.

17. Wahba R, Franke M, Hellmich M, Kleinert R, Cingoz T, Schmidt MC, et al. Computed tomography Volumetry in preoperative living kidney donor assessment for prediction of Split renal function. Transplantation. 2016:100:1270-7.

18. Yanishi M, Kinoshita H, Yoshida T, Takayasu K, Yoshida K, Kawa G, et al. Comparison of renal scintigraphy and computed tomographic renal Volumetry for determining Split renal function and estimating posttransplant renal function. Transplant Proc. 2015;47:2700-2.

19. Gardan E, Jacquemont L, Perret C, Heudes PM, Gourraud PA, Hourmant M, et al. Renal cortical volume: high correlation with pre- and post-operative renal function in living kidney donors. Eur J Radiol. 2018;99:118-23.
20. Yakoubi R, Autorino R, Kassab A, Long JA, Haber GP, Kaouk JH. Does preserved kidney volume predict 1 year donor renal function after laparoscopic living donor nephrectomy? Int J Urol. 2013;20:931-4.

21. Fananapazir G, Benzl R, Corwin MT, Chen LX, Sageshima J, Stewart SL, et al. Predonation volume of future remnant cortical kidney helps predict Postdonation renal function in live kidney donors. Radiology. 2018;288:153-7.

22. Jeon HG, Lee SR, Joo DJ, Oh YT, Kim MS, Kim YS, et al. Predictors of kidney volume change and delayed kidney function recovery after donor nephrectomy. J Urol. 2010;184:1057-63.

23. Lenihan CR, Busque S, Derby G, Blouch K, Myers BD, Tan JC. Longitudinal study of living kidney donor glomerular dynamics after nephrectomy. J Clin Invest. 2015;125:1311-8.

24. Blantz RC, Steiner RW. Benign hyperfiltration after living kidney donation. J Clin Invest. 2015;125:972-4.

25. Yoon YE, Choi KH, Lee KS, Kim KH, Yang SC, Han WK. Impact of metabolic syndrome on postdonation renal function in living kidney donors. Transplant Proc. 2015:47:290-4.

26. Ohashi Y, Thomas G, Nurko S, Stephany B, Fatica R, Chiesa A, et al. Association of metabolic syndrome with kidney function and histology in living kidney donors. Am J Transplant. 2013;13:2342-51.

27. Alexander MP, Patel TV, Farag YM, Florez A, Rennke HG, Singh AK. Kidney pathological changes in metabolic syndrome: a cross-sectional study. Am J Kidney Dis. 2009;53:751-9.

28. Choi KH, Lee SR, Hong YK, Park DS. Compensatory structural and functional adaptation after nephrectomy in obese patients according to waist circumference. Urology. 2017:104:115-21.

29. Weisinger JR, Kempson RL, Eldridge FL, Swenson RS. The nephrotic syndrome: a complication of massive obesity. Ann Intern Med. 1974;81:440-7.

30. Rea DJ, Heimbach JK, Grande JP, Textor SC, Taler SJ, Prieto M, et al. Glomerular volume and renal histology in obese and non-obese living kidney donors. Kidney Int. 2006;70:1636-41.

31. Goumenos DS, Kawar B, El Nahas M, Conti S, Wagner B, Spyropoulos C, et al. Early histological changes in the kidney of people with morbid obesity. Nephrol Dial Transplant. 2009;24:3732-8.

32. Tent H, Sanders JS, Rook M, Hofker HS, Ploeg RJ, Navis G, et al. Effects of preexistent hypertension on blood pressure and residual renal function after donor nephrectomy. Transplantation. 2012:93:412-7.

33. Taner T, Iqbal CW, Textor SC, Stegall MD, Ishitani MB. Compensatory hypertrophy of the remaining kidney in medically complex living kidney donors over the long term. Transplantation. 2015;99:555-9.

34. Tan JC, Busque S, Workeneh B, Ho B, Derby G, Blouch KL, et al. Effects of aging on glomerular function and number in living kidney donors. Kidney Int. 2010;78:686-92.

35. Lenihan CR, Busque S, Derby G, Blouch K, Myers BD, Tan JC. The association of predonation hypertension with glomerular function and number in older living kidney donors. J Am Soc Nephrol. 2015;26:1261-7.

36. Fesler P, Mourad G, du Cailar G, Ribstein J, Mimran A. Arterial stiffness: an independent determinant of adaptive glomerular hyperfiltration after kidney donation. Am J Physiol Renal Physiol. 2015;308:F567-71.

\section{Ready to submit your research? Choose BMC and benefit from:}

- fast, convenient online submission

- thorough peer review by experienced researchers in your field

- rapid publication on acceptance

- support for research data, including large and complex data types

- gold Open Access which fosters wider collaboration and increased citations

- maximum visibility for your research: over $100 \mathrm{M}$ website views per year

At $\mathrm{BMC}$, research is always in progress.

Learn more biomedcentral.com/submissions 